\title{
不同密度垄上三行栽培中行降密对大豆产量影响效果
}

杨殿金

黑龙江省格球山农场

DOI:10.32629/as.v2i4.1611

[摘 要] 本试验选取三个栽培密度,在三个密度的基础上进行边行增密、中行降密、总量相等的栽培方法,探索不同栽培方法对 大豆产量的影响,试验得出,在低密度栽培 “36 万株/公顷”条件下,大垄两行栽培有利于大豆增产; 在中密度栽培 “40 万株/公顷” 条件下, 大垄三行中行降密 50\%有利于大豆增产; 在高密度栽培 “45 万株/公顷” 条件下, 大垄三行产量不及大垄四行栽培增产。 [关键词] 大豆; 大垄三行; 密度; 产量

\section{1 试验设计及处理}

1. 1 试验设计

试验地前茬为玉米、秋整地、秋起垄, 地势平坦, 肥力中 等。本试验共设 10 个处理, 每处理 4 垄、垄距 1.1 米、行长 10 米, 小区面积 44 平方米, 试验面积 440 平方米。

\section{2 试验处理}

表1-1处理内容

\begin{tabular}{|c|c|c|c|c|}
\hline 处理 & 密度 & 边行粒数/平米 & 中行粒数/平米 & 边行粒数/平米 \\
\hline 1 & 36 & 18 & 0 & 18 \\
\hline 2 & 36 & 15 & 6 & 15 \\
\hline 3 & 36 & 12 & 12 & 12 \\
\hline 4 & 40 & 20 & 0 & 20 \\
\hline 5 & 40 & 17 & 6 & 17 \\
\hline 6 & 40 & 13 & 13 & 13 \\
\hline 7 & 45 & 23 & 0 & 23 \\
\hline 8 & 45 & 19 & 8 & 19 \\
\hline 9 & 45 & 15 & 15 & 15 \\
\hline $10(\mathrm{ck})$ & 45 & & & \\
\hline
\end{tabular}

注：对照为大垄四行常规栽培

\section{2 栽培方法}

播种前肥料定量分包, 机械施肥, 施肥量为N3. 5P4. 5K2, 施肥深度 10 厘米, 播种采用人工播种, 5 月 19 日进行深松作 业, 6 月 14 日及 24 日进行趟地作业, 生育期除草为人工除草。

\section{3 调查结果与分析}

表3-1大豆生长性状调查表

\begin{tabular}{|c|c|c|c|c|c|c|c|c|}
\hline \multirow{2}{*}{\multicolumn{2}{|c|}{ 试验处理 }} & \multirow{2}{*}{\multicolumn{2}{|c|}{\begin{tabular}{|l|} 
节数 \\
个/株 \\
\end{tabular}}} & \multirow{2}{*}{$\begin{array}{l}\text { 底英高 } \\
\text { 厘米 }\end{array}$} & \multirow{2}{*}{$\begin{array}{l}\text { 英数 } \\
\text { 个/株 }\end{array}$} & \multirow{2}{*}{$\begin{array}{l}\text { 粒数 } \\
\text { 个/株 }\end{array}$} & \multirow{2}{*}{ 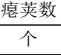 } & \multirow{2}{*}{$\begin{array}{c}\text { 百粒重 } \\
\text { 克 }\end{array}$} \\
\hline & & & & & & & & \\
\hline 1 & 边行 & 78.5 & 13 & 18.5 & 19 & 51 & 0 & 25.4 \\
\hline \multirow{2}{*}{2} & 边行 & 79.4 & 13 & 18.3 & 19 & 54 & 1 & \multirow{2}{*}{24.9} \\
\hline & 中行 & 77.3 & 13 & 20.5 & 17 & 52 & 0 & \\
\hline \multirow{2}{*}{3} & 边行 & 80.8 & 14 & 15.5 & 23 & 52 & 1 & \multirow{2}{*}{25.7} \\
\hline & 中行 & 80.0 & 13 & 19.2 & 15 & 40 & 1 & \\
\hline 4 & 边行 & 80.5 & 14 & 21.6 & 19 & 51 & 0 & 25.3 \\
\hline \multirow{2}{*}{5} & 边行 & 79.2 & 13 & 18.7 & 19 & 54 & 0 & \multirow{2}{*}{26.1} \\
\hline & 中行 & 81.5 & 14 & 19.6 & 17 & 48 & 1 & \\
\hline \multirow{2}{*}{6} & 边行 & 79.7 & 14 & 21.2 & 18 & 52 & 1 & \multirow{2}{*}{25.7} \\
\hline & 中行 & 78.3 & 13 & 20.5 & 16 & 46 & 1 & \\
\hline 7 & 边行 & 81.0 & 13 & 21.6 & 18 & 46 & 1 & 25.2 \\
\hline \multirow{2}{*}{8} & 边行 & 82.2 & 13 & 17.5 & 16 & 43 & 1 & \multirow{2}{*}{26.4} \\
\hline & 中行 & 82.5 & 13 & 22.0 & 15 & 48 & 0 & \\
\hline \multirow{2}{*}{9} & 边行 & 81.6 & 13 & 20.5 & 17 & 48 & 1 & \multirow{2}{*}{25.4} \\
\hline & 中行 & 77.8 & 12 & 19.8 & 13 & 37 & 1 & \\
\hline 10 (ck) & & 82.5 & 13 & 22 & 16 & 44 & 1 & 25.9 \\
\hline
\end{tabular}

从调查表来看, 试验处理大豆株高最大相差 5.1 厘米, 总 体相差较小, 其中大垄三行的 6 个处理, 中行与边行株高相差 不明显, 无明显规律。从大垄三行栽培的 6 个处理来看, 边行 单株荚数均高于中行单株荚数, 说明边行植株结荚能力普遍 好于中行, 从处理的密度来看, 密度越小的处理单株荚数相 对越多。

从试验设计的 10 个处理来看, 在 36 万株/公顷的密度情 况下, 中边比 $1: 1$ 处理好于 $0.5: 1.25$ 好于 $0: 1.5$, 说明此时三 行均匀分布对大豆结荚最为有利; 在 40 万株/公顷的密度情 况下, 三种栽培比例结荚能力相差不明显; 在 45 万株/公顷密 度情况下, $0: 1.5$ 好于 $1: 1$ 好于 $0.5: 1.25$ 。

从大垄三行栽培的 6 个处理来看, 边行单株粒数普遍好 于中行, 从 “中边比” 来看, $0.5: 1.25$ 的处理中行株粒数好于 $1: 1$ 处理的中行株粒数。

单株粒数是大豆产量构成的重要指标之一, 从试验设计的 10 个处理来看, 36 与 40 万株/公顷处理的单株粒数高于 45 万株/公 顷。在36万株/公顷的密度情况下，“中边比” 0.5:1.25的处理表 现好于其他两处理; 在 40万株/公顷的密度情况下, 0.5:1.25的处 理表现好于其他两处理; 在 45 万株/公顷密度情况下, $1: 1$ 的处理 表现好于其他两处理。即在栽培密度较低的情况下, 采用 “中边 比” 为 $0.5: 1.25$ 的栽培方式较好; 在栽培密度较高的情况下, 采 用“中边比”为 $1: 1$ 的栽培方式较好, 说明随着栽培密度发生变化, 最佳的中行与边行栽培比例随之变化。

表3-2大豆产量结果表

\begin{tabular}{|c|c|c|c|c|c|}
\hline \multirow{2}{*}{ 处理 } & 小区产量 & 折合亩产 & 公顷产量 & 增产比 & \multirow{2}{*}{ 位次 } \\
\cline { 2 - 4 } & 44 平米/公斤 & 公斤 & 公斤 & \% & \\
\hline 1 & 13.4 & 203 & 3036 & 6.3 & 4 \\
\hline 2 & 12.7 & 193 & 2897 & 1.5 & 6 \\
\hline 3 & 13.3 & 202 & 3032 & 6.2 & 5 \\
\hline 4 & 13.4 & 203 & 3046 & 6.7 & 3 \\
\hline 5 & 13.9 & 211 & 3156 & 10.5 & 1 \\
\hline 6 & 13.7 & 208 & 3113 & 9.0 & 2 \\
\hline 7 & 12.1 & 183 & 2742 & -4.0 & 10 \\
\hline 8 & 12.3 & 186 & 2786 & -2.4 & 9 \\
\hline 9 & 12.3 & 187 & 2805 & -1.8 & 8 \\
\hline $10(\mathrm{ck})$ & 12.6 & 190 & 2855 & 0.0 & 7 \\
\hline
\end{tabular}

从产量结果表可以看出, 试验处理产量与常规处理之间 


\title{
浅谈优质水稻栽培技术
}

\author{
吴刚 \\ 黑龙江北大荒农业股份有限公司八五四分公司 \\ DOI:10.32629/as.v2i4.1642
}

[摘 要] 水稻属于禾本科一年生草本, 稻属。它是由普通野生稻经长期的自然选择和人工选择共同作用下演变而来的。稻米 营养价值较高, 与其他谷物相比较, 它含粗纤维最少, 各种营养成分容易消化和吸收, 适宜人体需要。尤其是优质稻米深受人们的 喜爱,目前市场上供不应求。

[关键词] 优质水稻; 栽培技术; 播种

\section{1 优质水稻应具备的条件}

优质水稻除了丰产、抗性强、种植范围广之外, 还需要 具备好看、好吃、营养好、卫生好等四个特点。

\section{2 影响水稻品质的主要因素}

影响水稻品质的因素包括很多方面, 总结起来主要包括 遗传因素和非遗传因素。遗传因素就是品种, 非遗传因素包 括气候、土壤、肥料、水分、农药等。

\section{3 优质水稻高产配套技术}

科学确定保优栽培方案稻米的品质是遗传和环境的统 一, 遗传是高产的基础, 而环境又影响它的表现。根据研究显 示, 气象因素、土壤质地、土壤水分、肥料、农药及栽培管 理措施对稻米的品质和食味都有影响。同一优质稻品种在不 同的季节生产出来的粮米可能是不同的等级; 不同的栽培密 度会造成直链淀粉含量的差异; 不同的施氮水平会影响蛋白 质含量的高低; 土壤的优质稻品种由于种性不同而要求不同 的栽培密度; 同一优质稻品种, 由于季节不同, 要求的密度也 不同; 氮肥分配比例依品种的种性及季节变化。因此, 必须 针对一个特定的优质稻品种, 确定该品种的最佳保优栽培 方案。

\section{存在一定差异, 其中最大增产幅度为 $10.5 \%$, 最大减产幅度为} $4 \%$, 说明不同的处理水平对产量有较为明显的影响。

从产量趋势来看, $4 、 5 、 6$ 处理密度为 40 万株/公顷, 其产 量明显高于对照处理; $1 、 2 、 3$ 处理密度为 36 万株/公顷其产 量高于对照处理; $7 、 8 、 9$ 处理密度为 45 万株/公顷其产量低 于对照产量。从 “中边比”来看, 40万株/公顷处理中 $0.5: 1.25$ 表现较好; 36 万株/公顷处理中 $0: 1.5$ 表现较好; 45 万株/公 顷处理中 $1: 1$ 表现较好, 但产量较对照减产 $1.8 \%$ 。即在低密度 栽培条件下, 大垄两行栽培有利于大豆增产; 在中密度栽培 条件下, 中行降密 $50 \%$ 有利于大豆增产; 在高密度栽培条件下, 大垄三行产量不及大垄四行栽培增产。

\section{4 结论}

从试验因素对大豆生长性状指标的影响分析, 试验因素 对大豆株高影响较小, 对单株英数及粒数影响趋势基本相同, 从试验设计的 10 个处理来看, 在栽培密度较低的情况下, 采

\section{1 选择优良品种}

选择优良品种是生产优质水稻的重要基础。应该因地制 宜选择适合本地区生产的优质、高产、抗性强的品种。

\section{2 适期播种}

适期播种、移栽是生产优质水稻的关键。要根据水稻生 长的关键时期安排水稻的播种期, 包括: 抽穗扬花、灌浆、 结实期, 要使这 3 个关键时期的温度适宜。

水稻壮积的标准是根系发达, 颜色发白, 秧苗基部扁粗, 健壮, 夜色浓绿不披垂, 幼苗均匀整齐、积龄适宜。抛种和旱 育秋具有早生快发、返青期较短、结实率高、抗性强、有效 分藥率高等特点, 因此, 旱育秧和抛种是生产优质水稻的最 佳选择。生产优质常规水稻的旱育种播种量为每平方米苗床 播45-50克。播种时要采用精播器进行播种, 达到均匀播种的 目的。另外, 可采用 “壮秧剂”、“旱育保姆” 等物质缩短抛 秧和旱育秩的程序, 从而实现消毒床土、调酸、化控和培肥 等程序一次性完成、培育壮秧的目的。

\section{3 适当稀植}

适当稀植是培育壮秧、生产优质水稻的关键措施之一。 同时, 水稻的栽培密度对水稻品质的影响也较大。在保证肥
用 “中边比” 为 $0.5: 1.25$ 的栽培方式较好; 在栽培密度较高 的情况下, 采用 “中边比” 为 $1: 1$ 的栽培方式较好, 说明随着 栽培密度发生变化, 最佳的中行与边行栽培比例随之变化。

从产量趋势来看, 在低密度栽培“ 36 万株/公顷”条件下, 大垄两行栽培有利于大豆增产, 增产幅度为 $6.2 \%$; 在中密度 栽培 “ 40 万株/公顷” 条件下, 大垄三行中行降密 $50 \%$ 有利于 大豆增产, 增产幅度为 $10.5 \%$; 在高密度栽培 “ 45 万株/公顷” 条件下, 大垄三行产量不及大垄四行栽培增产。

\section{[参考文献]}

[1]于静波,张永坤.大豆垄上三行栽培技术总结[J].农民 致富之友,2019(02):33.

[2]佛明珠. 大豆垄上三行密植栽培技术解析[J]. 农业与 技术,2018(20):128.

[3]朱旭良.马铃薯大垄三行栽培模式与机械化种植技术 研究[J].新农业,2018(19):9-10. 